Research Article

\title{
Influence of No-Tillage on Soil Organic Carbon, Total Soil Nitrogen, and Winter Wheat (Triticum aestivum L.) Grain Yield
}

\author{
Peter Omara $\mathbb{D}^{1},{ }^{1,2}$ Lawrence Aula $\mathbb{D}^{1},{ }^{1}$ Elizabeth M. Eickhoff, ${ }^{1}$ Jagmandeep S. Dhillon, \\ Tyler Lynch, ${ }^{1}$ Gwendolyn B. Wehmeyer, ${ }^{1}$ and William Raun ${ }^{1}{ }^{1}$ \\ ${ }^{1}$ Department of Plant and Soil Sciences, Oklahoma State University, 74078 Stillwater, OK, USA \\ ${ }^{2}$ Department of Agronomy, Gulu University, P.O. Box 166, Gulu, Uganda \\ Correspondence should be addressed to Peter Omara; peter.omara@okstate.edu
}

Received 13 May 2019; Revised 19 July 2019; Accepted 21 August 2019; Published 1 October 2019

Academic Editor: Rodomiro Ortiz

Copyright (c) 2019 Peter Omara et al. This is an open access article distributed under the Creative Commons Attribution License, which permits unrestricted use, distribution, and reproduction in any medium, provided the original work is properly cited.

\begin{abstract}
No-tillage (NT) can improve soil properties and crop yield. However, there are contrasting reports on its benefits compared to conventional tillage (CT). Dataset (2003-2018) from long-term continuous winter wheat (Triticum aestivum L.) experiments 222 (E222) at Stillwater and 502 (E502) at Lahoma in Oklahoma, USA, established in 1969 and 1970, respectively, was used. Both experiments were managed under CT until 2010 and changed to NT in 2011. In each tillage system, treatments included nitrogen (N) rates at E222 $\left(0,45,90\right.$, and $\left.135 \mathrm{~kg} \cdot \mathrm{N} \cdot \mathrm{ha}^{-1}\right)$ and E502 $\left(0,22.5,45,67,90\right.$, and $\left.112 \mathrm{~kg} \cdot \mathrm{N} \cdot \mathrm{ha}^{-1}\right)$. The objective was to determine the change in wheat grain yield, soil organic carbon (SOC), and total soil nitrogen (TSN) associated with the change to NT. Grain yield was recorded, and postharvest soil samples taken from $0-15 \mathrm{~cm}$ were analyzed for TSN and SOC. Average TSN and SOC under NT were significantly above those under CT at both locations while grain yield differences were inconsistent. Under both tillage systems, grain yield, TSN, and SOC increased with N rates. At E222, grain yield, TSN, and SOC under NT were 23\%, 17\%, and $29 \%$, respectively, more than recorded under CT. At E502, grain yield was lower under NT than CT by $14 \%$ while TSN and SOC were higher by $11 \%$ and $13 \%$, respectively. Averaged over experimental locations, wheat grain yield, TSN, and SOC were 5\%, $14 \%$, and $21 \%$, respectively, higher under NT compared to CT. Therefore, NT positively influenced grain yield, TSN, and SOC and is likely a sustainable long-term strategy for improving soil quality and crop productivity in a continuous monocropping system.
\end{abstract}

\section{Introduction}

The depletion of soil resources as a result of poor production practices and the subsequent decline in crop yields has resulted in a search for sustainable approaches in crop production. No-tillage (NT) production systems, synonymous with zero tillage or conservation agriculture and sometimes minimum tillage (MT), is one of these sustainable crop production approaches sought by scientists around the world [1]. This approach has gained attention in the past years, and there is a growing trend for adoption by crop producers globally. Derpsch et al. [2] reported a world adoption rate of $6 \mathrm{M}$ ha per year between 1999 and 2009 where field crop area grew to $111 \mathrm{M}$ ha. By 2013, the land area under NT increased to $157 \mathrm{Mha}$, equivalent to approximately $11 \%$ of the total field production area [3]. In 2016 , the total global land area increased to $180 \mathrm{Mha}$, corresponding to approximately $12.5 \%$ [4]. The global increase in the rate of adoption and expansion of land area under NT is a result of numerous benefits associated with this farming practice. Generally, the benefits of NT originate from the three main principles: reduced soil disturbance, improved soil cover from crop residues, and increased species diversity through crop rotation $[5,6]$. Therefore, the improvement in soil's chemical and physical properties such as SOC, total porosity, and water holding capacity, among others under NT follow these principles [7]. 
Soil organic carbon and TSN are indicators of soil quality and provide structural stability to the soil matrix. However, there is a significant reduction in the rate of buildup and possible depletion under the CT system $[8,9]$. Halvorson et al. [10] reported a decreasing pattern in SOC as NT $<\mathrm{MT}<\mathrm{CT}$ where the most SOC is retained under NT. Practices that limit soil disturbance and encourage residue retention help in the restoration of these important soil quality parameters. Farooq and Siddique [1] asserted that NT increases SOC content by adding fresh plant residues that protect the enriched topsoil from rapid chemical and physical weathering. On sloping terrain, the implementation of NT leads to SOC accumulation by reducing the rate of severe soil erosion [11]. The retention of the residue on the surface of the soil through NT also helps in moderating temperature and moisture fluctuations. These abiotic factors are in turn responsible for controlling the rate of accumulation of SOC.

In addition to the improvement of soil structural stability, NT plays an important role in the reduction of production costs through reduced labor requirements for land tilling. It is important to note, however, that this approach requires a particular type of equipment for seed drilling [5]. This could be a setback for farmers in developing countries that are yet to adopt the use of such implements. Additionally, in developed countries, the initial cost of switching implements or reconfiguring the existing equipment to accommodate for NT is high, and this seems to be a reason why producers are sometimes reluctant to adopt the practice [12].

Other NT benefits relating to the improvement in crop productivity may depend on the specific production environment. For instance, Devita et al. [13] reported that the contribution of NT to grain yield improvement may be realized in environments where precipitation is less than $300 \mathrm{~mm}$ per year. According to their findings, NT may not significantly produce higher grain yield compared to the CT system in areas with adequate precipitation. This is especially true if moisture conservation and improved water infiltration are important $[14,15]$. Hansen et al. [16] added that NT is a key management strategy with the apparent temporal and spatial climate variability. Furthermore, grain yield improvement depends on the length of production under NT practice [17]. Much as structural stability could be realized under NT within a short-term production period, grain yield benefits under NT are possible after long-term crop production cycles.

Some researchers report decreases in root growth and grain yield under NT for many reasons. Soil compaction, which decreases soil aeration and water infiltration, can in some cases reduce crop yield under NT [18]. The decrease in crop yield can also result from reduced $\mathrm{N}$ use efficiency of surface-applied urea due to volatilization losses [19]. The use of slow-release $\mathrm{N}$ fertilizers such as sulfur-coated urea and delayed urea application may improve the efficiency of fertilizer N under NT. Arvidsson et al. [20] reported a $10 \%$ decline in crop yield under NT relative to the CT system. This decrease in yield was attributed to poor crop establishment due to improper seedbed preparation that they referred to as "lack of seedbed."
In addition to yield reduction, NT has also been scrutinized for the emergence of herbicide-resistant weeds as a result of overdependence on the use of chemicals [21]. The latter can increase the risk of subsurface flow of chemicals that can increase the potential for environmental pollution. Therefore, the agronomic and environmental impact or the success of NT is environment-specific, and the improvement in soil's chemical and physical properties under NT translates to the improvement in crop yield after long-term implementation of this practice. Data used in this study were taken from two long-term experiments established in the 1960s under CT practice at the time when limited research reports on the importance of NT practice were available. In the 1990s and early 2000, many research works indicated the superiority of NT over CT practice in improving crop yield and soil properties. This prompted a widespread adoption by farmers in the United States' Great Plains [16, 22] and was the main reason for the conversion of these long-term experiments from CT to NT. However, studies documenting the comparative benefits between CT and NT on TSN, SOC, and wheat grain yield from a long-term perspective in this region are scarce. Therefore, the objective of this study was to determine the change in wheat grain yield, SOC, and TSN associated with the conversion from CT to NT.

\section{Materials and Methods}

2.1. Site Description. This study used data from two longterm experiments: experiment 222 (E222) and experiment 502 (E502). The E222 trial was established in 1969 on a welldrained, deep, and slowly permeable Kirkland silt loam (fine, mixed, thermic Udertic Paleustoll) at the Agronomy Research Station in Stillwater, Oklahoma, USA, with an altitude of 272 masl. Experiment 502, established in 1970, is located on a well-drained, deep, and moderately permeable Grant silt loam (fine-silty, mixed, thermic Udic Argiustoll) at the North Central Research Station in Lahoma, Oklahoma, USA, with an altitude of 396 masl. For both experimental sites, total rainfall and average air temperature were computed for the winter wheat growing periods (October-June) for each year reported (Figure 1). Comparisons were made for varieties planted under both tillage systems to determine whether or not significant differences existed between the tillage systems with the same wheat variety at both sites (Figure 2).

2.2. Experimental Design and Management. The experimental design at E222 was a randomized complete block with thirteen treatments and four replications. Only 4 of the treatments, $1,2,3$, and 4 with $0,45,90$, and $135 \mathrm{~kg} \cdot \mathrm{N} \cdot \mathrm{ha}^{-1}$, respectively, were used for this report (Table 1). Each of these treatments had fixed phosphorus (P) and potassium (K) rates of 29 and $37 \mathrm{~kg} \cdot \mathrm{ha}^{-1}$, respectively. Fertilizer $\mathrm{N}$ was applied as urea (46-0-0) preplant. The treatment with the maximum $\mathrm{N}$ rate $\left(135 \mathrm{~kg} \cdot \mathrm{ha}^{-1}\right)$ was split, $67.5 \mathrm{~kg} \cdot \mathrm{ha}^{-1}$ preplant and another $67.5 \mathrm{~kg} \cdot \mathrm{ha}^{-1}$ applied midseason. Fertilizer $\mathrm{P}$ and $\mathrm{K}$ were applied preplant as triple superphosphate $(0$ 22-0) and potassium chloride (0-0-52), respectively. The 




Figure 1: Total rainfall (October-June) and average air temperature (October-June) at E222 (Stillwater) and E502 (Lahoma), Oklahoma, USA, 2003-2017.

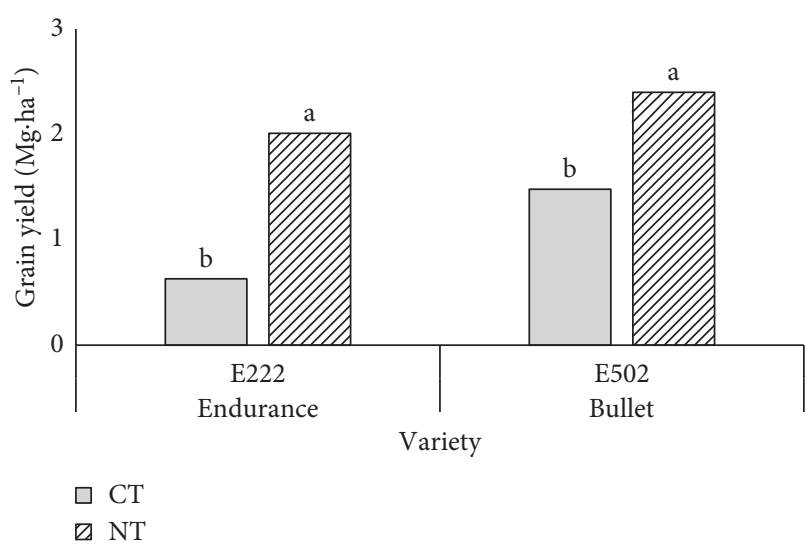

FIGURE 2: Average wheat grain yield for varieties planted under CT (conventional tillage) and NT (no-tillage) at E222 (Stillwater) and E502 (Lahoma), Oklahoma USA; different letters indicate significant differences between varieties at each site at $p<0.05$; Tukey's HSD test.

design at E502 was a randomized complete block with fourteen treatments and four replications. For this report, however, only six treatments, $2,3,4,5,6$, and 7 with $0,22.5$, $45,67,90$, and $112 \mathrm{~kg} \cdot \mathrm{N} \cdot \mathrm{ha}^{-1}$, respectively, were used (Table 1). For each of these treatments, $\mathrm{P}$ and $\mathrm{K}$ were applied at fixed rates of 20 and $56 \mathrm{~kg} \cdot \mathrm{ha}^{-1}$, respectively. Nitrogen, $\mathrm{P}$, and $\mathrm{K}$ were applied preplant as urea (46-0-0), triple superphosphate (0-22-0), and potassium chloride (0-0-52), respectively. Both E222 and E502 were established as a continuous winter wheat-summer fallow under the CT system until 2010 where disc harrow and chisel plough were used in the experimental fields prior to planting seeds. Presently, they are managed under NT with no cultivation prior to seed drilling, and all residues are left on the soil surface after harvest [23]. Under the NT practice, Roundup (glyphosate) and WeedMaster (dicamba: 12.4\% and 2,4-D:
TABLE 1: Treatment arrangement with preplant $\mathrm{N}, \mathrm{P}$, and $\mathrm{K}$ rates at E222 (Stillwater) and E502 (Lahoma), Oklahoma, USA.

\begin{tabular}{lccc}
\hline Treatment number & $\begin{array}{c}\mathrm{N} \text { rate } \\
\left(\mathrm{kg} \cdot \mathrm{N} \cdot \mathrm{ha}^{-1}\right)\end{array}$ & $\begin{array}{c}\mathrm{P} \text { rate } \\
\left(\mathrm{kg} \cdot \mathrm{P} \cdot \mathrm{ha}^{-1}\right)\end{array}$ & $\begin{array}{c}\mathrm{K} \text { rate } \\
\left(\mathrm{kg} \cdot \mathrm{K} \cdot \mathrm{ha}^{-1}\right)\end{array}$ \\
\hline \multicolumn{4}{c}{$\mathrm{E} 222$} \\
1 & 0 & 29 & 37 \\
2 & 45 & 29 & 37 \\
3 & 90 & 29 & 37 \\
4 & $135^{\dagger}$ & 29 & 37 \\
\hline \multicolumn{4}{c}{$\mathrm{E} 502$} \\
2 & 0 & 20 & 56 \\
3 & 22.5 & 20 & 56 \\
4 & 45 & 20 & 56 \\
5 & 67 & 20 & 56 \\
7 & 90 & 20 & 56 \\
\hline
\end{tabular}

$\mathrm{N}=$ nitrogen applied as urea $(46-0-0) ; \mathrm{P}=$ phosphorus applied as triple superphosphate (0-22-0); $\mathrm{K}=$ potassium applied as potassium chloride (0-052). ${ }^{\dagger}$ Split applied with $67 \mathrm{~kg} \cdot \mathrm{N} \cdot \mathrm{ha}^{-1}$ preplant and $67 \mathrm{~kg} \cdot \mathrm{N} \cdot \mathrm{ha}^{-1}$ midseason.

$35.7 \%$ ) herbicides were applied every year at a rate of 1 $2 \mathrm{Lha}^{-1}$, depending on the weed pressure. Winter wheat seeds of $100 \mathrm{~kg} \cdot \mathrm{ha}^{-1}$ in weight were drilled using the Great Plains 2010 Drill (Great Plains Ag, Salina, Kansas, USA). Planting dates varied from one year to another, but seeds were generally drilled in October (1st to 30th) of each year reported in this study (2003-2018). Both experimental fields were managed under rain-fed conditions with no irrigation water applied.

2.3. Sampling and Sample Processing. Winter wheat grain yield data used in this report were obtained over eight years for each tillage system from 2003 to 2010 and from 2011 to 2018 under CT and NT, respectively. Experimental plots were harvested at maturity using a Massey Ferguson 8XP self-propelled combine. Grain yields were adjusted to $12.5 \%$ 
moisture content. Data on SOC and TSN were available for only four years each under CT and NT, not eight years as reported for grain yield. Under CT, data were obtained from 2007 to 2010 while under NT, data were obtained from 2011 to 2014. In July of each year, 15-20 postharvest soil cores were collected from $0-15 \mathrm{~cm}$ soil depth and composited for each treatment. These samples were oven-dried for 48 hours at $65^{\circ} \mathrm{C}$ and later ground to pass a $1 \mathrm{~mm}$ sieve. The determination of SOC and TSN was completed using the LECO Truspec CN dry combustion analyzer [24]. The LECO CN 628 dry combustion analyzer was used. For each sample, $200 \mathrm{mg}$ of soil by treatment and replication was weighed, wrapped in aluminum foil, and combusted at $950^{\circ} \mathrm{C}$.

2.4. Statistical Analysis. Data were analyzed using the SAS statistical software package [25]. The GLM procedure was used to conduct the analysis of variance appropriate for a randomized complete block design for grain yield, TSN, and SOC. Single-degree-of-freedom orthogonal contrasts were used to compare grain yield, TSN, and SOC treatment means from CT and NT $[26,27]$. To associate grain yield with soil quality parameters, the relationships between grain yield and TSN as well as grain yield and SOC were evaluated using the SAS PROC REG procedure [25].

\section{Results}

3.1. Wheat Grain Yield. Analysis of variance showed an overall significant difference $(p<0.05)$ in mean grain yield between CT and NT at E222 (Table 2). For specific N rates, no significant $(p>0.05)$ difference was observed between CT and NT in the check plot $\left(0 \mathrm{~kg} \cdot \mathrm{N} \cdot \mathrm{ha}^{-1}\right)$. However, significant $(p<0.05)$ grain yield differences were observed at 45,90 , and $135 \mathrm{~kg} \cdot \mathrm{N} \cdot \mathrm{ha}^{-1}$, and yields were 30,21 , and $21 \%$ higher under NT than seen under the CT system, respectively. Generally, grain yield across all treatments was $23 \%$ higher under NT than that observed under CT. Grain yield increased with N rates under both practices. Although the increase was generally higher under NT for all N application rates, the trend was similar to that observed under CT (Figure 3(a)).

At E502, overall results showed a significant difference $(p<0.05)$ in grain yield mean values between CT and NT (Table 3). When specific and equal $\mathrm{N}$ rates under CT and NT were in contrast to each other, no grain yield differences were observed at $0,22.5,45,67$, and $90 \mathrm{~kg} \cdot \mathrm{N} \cdot \mathrm{ha}^{-1}$. However, a significant difference $(p<0.05)$ was observed with an application rate of $112 \mathrm{~kg} \cdot \mathrm{N} \cdot \mathrm{ha}^{-1}$ where grain yield under CT was $0.7 \mathrm{Mg} \cdot \mathrm{ha}^{-1}$ higher than recorded under NT. Generally, average wheat grain yield across treatments was $14 \%$ higher under CT than NT. This result did not mirror the observation at E222 where grain yields at all $\mathrm{N}$ rates were higher under NT than under the CT system.

Overall analysis indicates significant differences $(p<0.05)$ in grain yield of wheat varieties planted at both sites. Varieties that were planted under both tillage systems also showed significant differences in grain yield. At E502, the variety "Bullet" yielded significantly higher under NT than CT (Figure 2). Similarly, comparison of varieties at E222 showed
TABLE 2: Treatment means for grain yield, TSN, and SOC and single-degree-of-freedom orthogonal contrasts between CT and NT treatments at E222 (Stillwater), Oklahoma, USA, 2003-2018.

\begin{tabular}{|c|c|c|c|c|c|}
\hline Treatment & Tillage & $\begin{array}{c}\text { N rate } \\
\left(\mathrm{kg} \cdot \mathrm{ha}^{-1}\right)\end{array}$ & 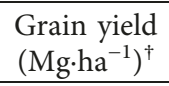 & $\begin{array}{c}\text { TSN } \\
\left(\mathrm{g} \cdot \mathrm{kg}^{-1}\right)^{\ddagger}\end{array}$ & $\begin{array}{c}\mathrm{SOC} \\
\left(\mathrm{g} \cdot \mathrm{kg}^{-1}\right)^{\ddagger}\end{array}$ \\
\hline \multicolumn{6}{|c|}{ Treatment means } \\
\hline 1 & $\mathrm{CT}$ & 0 & 1.32 & 0.80 & 8.53 \\
\hline 2 & $\mathrm{CT}$ & 45 & 1.53 & 0.88 & 9.14 \\
\hline 3 & $\mathrm{CT}$ & 90 & 1.94 & 0.91 & 9.61 \\
\hline 4 & $\mathrm{CT}$ & 135 & 2.04 & 0.97 & 10.05 \\
\hline CV (\%) & & & 49.4 & 13.5 & 8.2 \\
\hline 1 & NT & 0 & 1.70 & 0.99 & 12.07 \\
\hline 2 & NT & 45 & 2.17 & 1.03 & 13.15 \\
\hline 3 & NT & 90 & 2.45 & 1.11 & 13.61 \\
\hline 4 & NT & 135 & 2.59 & 1.15 & 14.02 \\
\hline CV (\%) & & & 42.3 & 24.2 & 38.7 \\
\hline \multicolumn{6}{|c|}{ Contrast $p$ value } \\
\hline 1 & $\begin{array}{c}\text { CT1 vs. } \\
\text { NT1 } \\
\text { CT2 }\end{array}$ & 0 & 0.1074 & 0.0247 & 0.0257 \\
\hline 2 & $\begin{array}{c}\text { vs. } \\
\text { NT2 } \\
\text { CT3 }\end{array}$ & 45 & 0.0060 & 0.0705 & 0.0119 \\
\hline 3 & $\begin{array}{l}\text { vs. } \\
\text { NT3 } \\
\text { CT4 }\end{array}$ & 90 & 0.0281 & 0.0180 & 0.0119 \\
\hline 4 & $\begin{array}{c}\text { vs. } \\
\text { NT4 }\end{array}$ & 135 & 0.0209 & 0.0345 & 0.0127 \\
\hline Average & $\begin{array}{c}\text { CT vs. } \\
\text { NT }\end{array}$ & & $<0.0001$ & $<0.0001$ & $<0.0001$ \\
\hline
\end{tabular}

$\mathrm{CV}=$ coefficient of variation; $\mathrm{CT}=$ conventional tillage; $\mathrm{NT}=$ no-tillage; TSN = total soil nitrogen; SOC = soil organic carbon; ${ }^{\dagger}$ treatment means for grain yield were obtained under CT (2003-2010) and NT (2011-2018); *treatment means for TSN and SOC were obtained under CT (2007-2010) and NT (2011-2014).

that "Endurance," planted under both tillage systems, yielded significantly higher under NT than under CT (Figure 2). The influence of tillage system was therefore independent of wheat varieties used in this study.

3.2. Total Soil Nitrogen. Total soil nitrogen at E222 was significantly different $(p<0.05)$ between CT and NT at $0 \mathrm{~kg} \cdot \mathrm{N} \cdot \mathrm{ha}^{-1}$ where the latter was $19 \%$ higher than the former. At $45 \mathrm{~kg} \cdot \mathrm{N} \cdot \mathrm{ha}^{-1}$, no significant difference $(p>0.05)$ in TSN accumulation was observed between CT and NT. Nevertheless, significant differences $(p<0.05)$ were observed at 90 and $135 \mathrm{~kg} \cdot \mathrm{N} \cdot \mathrm{ha}^{-1}$ where TSN was 18 and $16 \%$ higher under NT than observed under CT at the respective $\mathrm{N}$ rates. Considering average values across treatments, TSN was $17 \%$ higher under NT than recorded under CT. A pattern of buildup in TSN was observed for both practices (Figure 3(c)). Under NT, positive linear relationships between TSN and grain yield were observed across $\mathrm{N}$ rates (Table 4).

For E502, $\mathrm{N}$ application rates of $0,22.5,45$, and $67 \mathrm{~kg} \cdot \mathrm{N} \cdot \mathrm{ha}^{-1}$ at E502 did not result in a significant difference in TSN between CT and NT. Nonetheless, significant differences $(p<0.05)$ in TSN between NT and CT were seen at 90 and $112 \mathrm{~kg} \cdot \mathrm{N} \cdot \mathrm{ha}^{-1}$ where the NT produced 15 and $12 \%$ 


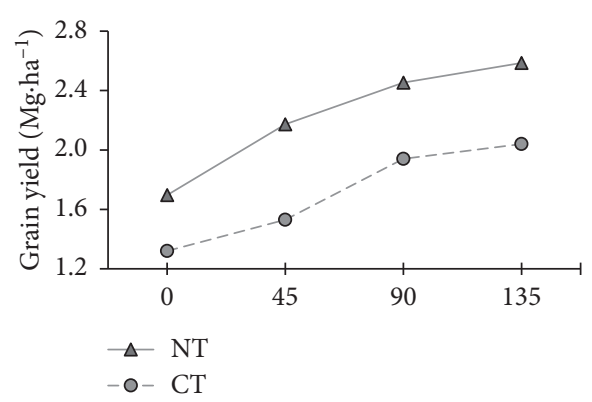

(a)

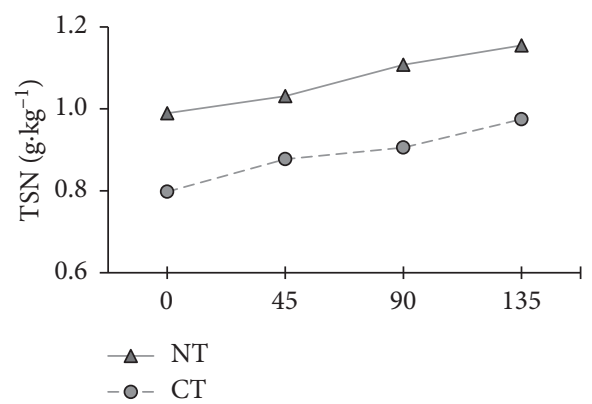

(c)

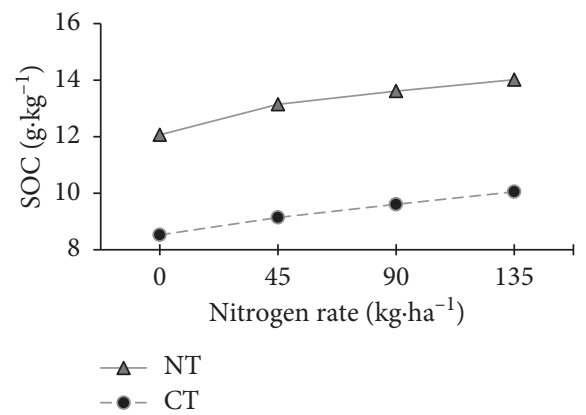

(e)

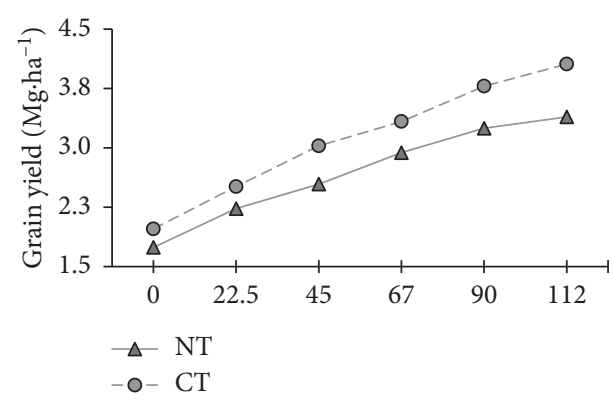

(b)

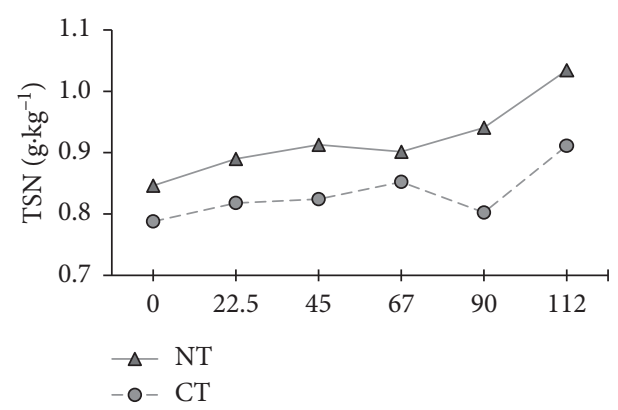

(d)

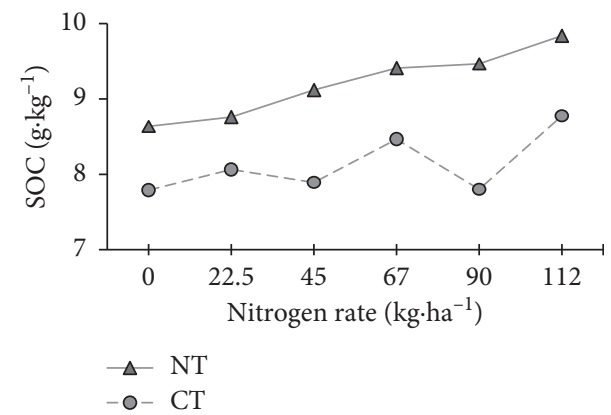

(f)

Figure 3: Changes in grain yield at E222 (a) and E502 (b); TSN at E222 (c) and E502 (d); SOC at E222 (e) and E502 (f) as influenced by different fertilizer rates under NT (no-tillage) and CT (conventional tillage).

higher TSN than for CT. Averaged across treatments, NT had $11 \%$ higher TSN than CT. The observation at E502 is similar to that at E222 although the latter was 6\% higher than the former. Unlike E222, the slopes of the linear relationship between TSN and grain yield under NT were negative for each $\mathrm{N}$ rate at E502 (Table 4).

3.3. Soil Organic Carbon. Significant differences $(p<0.05)$ in the buildup of SOC between CT and NT were observed in all treatments at E222. Soil organic carbon was 29, 30, 29, and $28 \%$ higher under NT than recorded under CT at $0,45,90$, and $135 \mathrm{~kg} \cdot \mathrm{N} \cdot \mathrm{ha}^{-1}$, respectively. This result does not show any pattern of percentage difference in the SOC buildup under NT with $\mathrm{N}$ rates although a nonsignificant trend for increased SOC with applied $\mathrm{N}$ was present for both practices (Figure 3(e)). It is also evident that the increase was higher under NT than CT. Averaged across treatments, SOC under NT was 29\% higher than that recorded for CT. Under NT, positive linear relationships between SOC and grain yield were observed across $\mathrm{N}$ rates (Table 4).
At E502, SOC accumulation between CT and NT was significantly different $(p<0.05)$ at all $\mathrm{N}$ application rates. At treatment levels of $0,22.5,45,67,90$, and $112 \mathrm{~kg} \cdot \mathrm{N} \cdot \mathrm{ha}^{-1}$, SOC under NT was $10,8,14,10,18$, and $11 \%$ higher, respectively, compared to that under CT. Averaged across all treatments, SOC was 13\% higher under NT than under CT. This result mirrored the observation at E222 with an overall significant difference between NT and CT under all N rates. However, the overall difference was 16\% higher at E222 than under E502. The linear relationships for each $\mathrm{N}$ rate between SOC and grain yield under NT had negative slopes at E502 and did not mirror observations at E222 (Table 4).

\section{Discussion}

4.1. Wheat Grain Yield. Results from the present study showed that grain yield under NT was significantly higher than that under the CT system. However, the yield benefit accrued under NT was not consistent across experimental sites. Overall, grain yield under NT was higher than that 
TABLE 3: Treatment means for grain yield, TSN, and SOC and single-degree-of-freedom orthogonal contrasts between CT and NT treatments at E502 (Lahoma), Oklahoma, USA, 2003-2018.

\begin{tabular}{|c|c|c|c|c|c|}
\hline Treatment & Tillage & $\mathrm{N}$ rate $\left(\mathrm{kg} \cdot \mathrm{ha}^{-1}\right)$ & Grain yield $\left(\mathrm{kg} \cdot \mathrm{ha}^{-1}\right)^{\dagger}$ & TSN $\left(\mathrm{g} \cdot \mathrm{kg}^{-1}\right)^{\ddagger}$ & SOC $\left(g \cdot \mathrm{kg}^{-1}\right)^{\ddagger}$ \\
\hline \multicolumn{6}{|c|}{ Treatment means } \\
\hline 2 & $\mathrm{CT}$ & 0 & 1.98 & 0.79 & 7.79 \\
\hline 3 & $\mathrm{CT}$ & 22.5 & 2.51 & 0.82 & 8.06 \\
\hline 4 & $\mathrm{CT}$ & 45 & 3.03 & 0.82 & 7.89 \\
\hline 5 & $\mathrm{CT}$ & 67 & 3.33 & 0.85 & 8.47 \\
\hline 6 & $\mathrm{CT}$ & 90 & 3.78 & 0.80 & 7.80 \\
\hline 7 & $\mathrm{CT}$ & 112 & 4.06 & 0.91 & 8.78 \\
\hline CV (\%) & & & 40 & 13.7 & 13.9 \\
\hline 2 & NT & 0 & 1.74 & 0.85 & 8.64 \\
\hline 3 & NT & 22.5 & 2.23 & 0.89 & 8.76 \\
\hline 4 & NT & 45 & 2.54 & 0.91 & 9.12 \\
\hline 5 & NT & 67 & 2.94 & 0.90 & 9.41 \\
\hline 6 & NT & 90 & 3.25 & 0.94 & 9.47 \\
\hline 7 & NT & 112 & 3.39 & 1.03 & 9.84 \\
\hline CV (\%) & & & 35 & 23.8 & 7.6 \\
\hline \multicolumn{6}{|c|}{ Contrast $p$ value } \\
\hline 2 & CT2 vs. NT2 & 0 & 0.3933 & 0.3471 & 0.0120 \\
\hline 3 & CT3 vs. NT3 & 22.5 & 0.3095 & 0.2469 & 0.0381 \\
\hline 4 & CT4 vs. NT4 & 45 & 0.0802 & 0.1545 & 0.0003 \\
\hline 5 & CT5 vs. NT5 & 67 & 0.1511 & 0.4287 & 0.0052 \\
\hline 6 & CT6 vs. NT6 & 90 & 0.0588 & 0.0269 & $<0.0001$ \\
\hline 7 & CT7 vs. NT7 & 112 & 0.0178 & 0.0486 & 0.0017 \\
\hline Average & CT vs. NT & & 0.0002 & 0.0006 & $<0.0001$ \\
\hline
\end{tabular}

$\mathrm{CV}=$ coefficient of variation; $\mathrm{CT}=$ conventional tillage; $\mathrm{NT}=$ no-tillage; $\mathrm{TSN}=$ total soil nitrogen; $\mathrm{SOC}=$ soil organic carbon; ${ }^{\dagger}$ treatment means for grain yield were obtained under CT (2003-2010) and NT (2011-2018); " treatment means for TSN and SOC were obtained under CT (2007-2010) and NT (2011-2014).

TABLE 4: Summary of relationships between wheat grain yield, TSN, and SOC under NT at E222 (Stillwater) and E502 (Lahoma), Oklahoma, USA, 2007-2014.

\begin{tabular}{|c|c|c|c|c|c|c|c|}
\hline \multirow{2}{*}{ Treatment } & \multirow{2}{*}{$\mathrm{N}$ rate $\left(\mathrm{kg} \cdot \mathrm{ha}^{-1}\right)$} & \multicolumn{3}{|c|}{ TSN vs. grain yield } & \multicolumn{3}{|c|}{ SOC vs. grain yield } \\
\hline & & $p$ value & $R^{2}$ & Equation & $p$ value & $R^{2}$ & Equation \\
\hline \multicolumn{8}{|c|}{ E222 } \\
\hline 1 & 0 & 0.0036 & 0.59 & $y=1777.8 x-727$ & 0.0076 & 0.53 & $y=412.15 x-2946$ \\
\hline 2 & 45 & 0.0058 & 0.55 & $y=2183.2 x-931$ & $<0.0001$ & 0.95 & $y=615.2 x-5020$ \\
\hline 3 & 90 & 0.2087 & 0.15 & $y=1139.8 x+376$ & 0.0029 & 0.6 & $y=418.36 x-2900$ \\
\hline 4 & 135 & 0.0951 & 0.25 & $y=1544.1 x-223$ & 0.0206 & 0.43 & $y=402.05 x-2840$ \\
\hline \multicolumn{8}{|c|}{ E502 } \\
\hline 2 & 0 & 0.0154 & 0.35 & $y=-2732.5 x+4280$ & 0.2003 & 0.11 & $y=-477.8 x+6094$ \\
\hline 3 & 22.5 & 0.0008 & 0.56 & $y=-3659.2 x+5745$ & 0.0491 & 0.25 & $y=-741.33 x+8983$ \\
\hline 4 & 45 & 0.004 & 0.46 & $y=-3571.1 x+6273$ & 0.0015 & 0.53 & $y=-1455.9 x+16290$ \\
\hline 5 & 67 & 0.0053 & 0.42 & $y=-5196.7 x+7919$ & 0.1457 & 0.14 & $y=-734.62 x+10194$ \\
\hline 6 & 90 & 0.0041 & 0.54 & $y=-5344.8 x+8852$ & 0.3068 & 0.09 & $y=-1059.8 x+13849$ \\
\hline 7 & 112 & 0.0133 & 0.44 & $y=-4621.5 x+9196$ & 0.0285 & 0.37 & $y=-1265 x+16803$ \\
\hline
\end{tabular}

E502 = experiment 502; E222 = experiment 222; $n=16$ for each treatment; NT =no-tillage; TSN $=$ total soil nitrogen; SOC = soil organic carbon.

under the CT system by $5 \%$ when averaged across locations. Although higher for NT, a trend for increased grain yield with $\mathrm{N}$ rates was observed at both sites and under both systems. The increase in grain yield with fertilizer $\mathrm{N}$ under NT was most likely due to improved $\mathrm{N}$ utilization. This is in agreement with the work by Triplett and Dick [28] reporting that NT improved fertilizer use efficiency. Improved soil structural stability under NT coupled with increases in potential mineralizable $\mathrm{N}$ could have had an impact on grain yield. Doran et al. [29] reported between 20 and $101 \mathrm{~kg} \cdot \mathrm{ha}^{-1}$ as potentially mineralizable $\mathrm{N}$ under NT compared to the CT system. In a maize-wheat sequence, Ghuman and Sur [30] observed an overall grain yield advantage of NT over CT, but noted that yields were much higher with the application of residue mulch of $3 \mathrm{Mg} \cdot \mathrm{ha}^{-1}$ from the previous season. From another perspective, Devita et al. [13] noted that the overall grain yield advantage for NT over CT was realized in environments where precipitation was less than $300 \mathrm{~mm}$ per year. In the current study, however, the average annual rainfall at both locations was above $300 \mathrm{~mm}$. Over the study period, the average annual rainfall was $715 \mathrm{~mm}$ and $856 \mathrm{~mm}$ at E502 and E222, respectively. With average grain yield comparatively lower at E222 than at E502, this demonstrates the advantage of the NT system in relatively low yielding 
environments. It is important to note that the gap between NT and CT was wider than observed at E502, again illustrating the positive impact of a NT system in low yielding environments. Overall, comparisons of varieties planted under both tillage systems showed that wheat grain yield under NT was greater than that under CT.

4.2. Total Soil Nitrogen. Total soil nitrogen at both locations increased with an increase in N applied for both CT and NT when averaged over treatments, consistent with several research reports [31-35]. Ortas et al. [36] explained that an increase in TSN with increased $\mathrm{N}$ fertilizer rate was a result of improved plant biomass production with decreased $\mathrm{C}: \mathrm{N}$ ratio. Even under CT, TSN increased with increase in $\mathrm{N}$ applied. In a long-term continuous CT system, Raun et al. [34] also observed an increase in TSN with increased fertilizer N rates. Generally, similar trends for increased TSN were seen for both systems although TSN under NT was significantly higher than that under CT. The current study showed that TSN was $14 \%$ higher for NT when compared to CT, and that was similar to a report by Mikha and Rice [37]. According to Havlin et al. [38], increased TSN under NT was greater for crop rotation practices with high surface residue compared to CT even at limited or no fertilizer N application. Malhi and Kutcher [39] also reported higher TSN under NT compared to CT when crop residue was returned to the soil surface. By design, NT automatically leaves the residue on the soil surface [40]. Consistent with these reports, the current study indicates that high fertilizer $\mathrm{N}$ input under NT improves TSN buildup better than under CT although positive linear relationships with grain yield were not consistent across locations.

4.3. Soil Organic Carbon. In general, SOC was significantly higher under NT than under the CT system at all experimental sites. The tendency of SOC to increase with $\mathrm{N}$ rates was observed under both systems. This is consistent with a report by Lafond et al. [41] who observed high SOC under high levels of $\mathrm{N}$ application. The high SOC under NT could be a result of increased biomass production associated with high $\mathrm{N}$ rates. At high $\mathrm{N}$ rates, increased biomass production compared to the control treatment with no $\mathrm{N}$ applied increases the possibility of surface buildup of SOC under NT $[23,33]$. In a long-term study, Havlin et al. [38] also reported greater SOC under NT compared to CT. However, the authors indicated that there was a tendency for soil to accumulate more SOC under a rotation system compared to continuous monocropping because of increased species diversity. The current study, under continuous monocropping practice, shows an average of $21 \%$ more SOC under NT than CT. From another perspective, the rate of SOC accumulation is likely dependent on how long production has taken place under NT. For instance, Lafond et al. [41] reported significantly higher SOC under long-term NT (39 years) compared to short-term NT (9 years). In their study, long-term NT produced $17 \%$ more SOC than shortterm NT from the $0-15 \mathrm{~cm}$ soil layer, while no differences were observed between samples obtained from a $15-30 \mathrm{~cm}$ soil depth. In the present study, the inconsistent positive linear relationships between NT and grain yield could be due to relatively shorter production cycle (8 years) under this practice or just a result of differences in the production environment. This implies that there will be major improvements in this parameter after 15 or 20 years. Dolan et al. [32] reported over $30 \%$ more SOC in a $0-20 \mathrm{~cm}$ soil layer under NT than CT. Under native prairie or long-term NT, the residue decomposition rate is slow, and surface accumulation explains the high $\mathrm{SOC}$ at $0-15 \mathrm{~cm}$. The CT practice aerates the soil system allowing for decomposition to take place much faster. In the process, more carbon is oxidized. Therefore, producers have to practice NT on a long-term basis in order to realize a significant improvement in soil quality and crop yield.

\section{Conclusion}

The current study examined the benefits of changing from CT to NT in a continuous winter wheat-summer fallow practice. Generally, the results showed an overall positive influence of NT on winter wheat grain yield, TSN, and SOC. However, the extent to which NT impacted these parameters varied with experimental locations, and they were more positive in low yielding environments. Results averaged over experimental locations and treatments indicate a 5\% yield benefit under NT over CT. Total soil N and SOC from a $0-15 \mathrm{~cm}$ soil depth under NT were higher than those under CT by $14 \%$ and $21 \%$, respectively. The small (5\%) increase in grain yield could be due to a shorter production cycle (8 years) under NT. This is consistent with a conclusion by Lafond et al. [41] that soil quality parameters and crop yield are additive under NT. Therefore, compared to CT, NT was a better alternative crop production practice and is likely a sustainable long-term strategy for improving soil quality and crop productivity in a continuous monocropping system.

\section{Data Availability}

The data used for this study is available from the corresponding author upon request.

\section{Conflicts of Interest}

The authors declare that there are no conflicts of interest regarding the publication of this paper.

\section{References}

[1] M. Farooq and K. H. Siddique, "Conservation agriculture: concepts, brief history, and impacts on agricultural systems," in Conservation Agriculture, Springer, Cham, Switzerland, 2015.

[2] R. Derpsch, T. Friedrich, A. Kassam, and H. Li, "Current status of adoption of no-till farming in the world and some of its main benefits," International Journal of Agricultural and Biological Engineering, vol. 3, no. 1, pp. 1-25, 2010.

[3] A. Kassam, T. Friedrich, R. Derpsch, and J. Kienzle, "Overview of the worldwide spread of conservation agriculture. Field actions science reports," The Journal of Field Actions, vol. 8, 2015. 
[4] A. Kassam, T. Friedrich, and R. Derpsch, "Global spread of conservation agriculture," International Journal of Environmental Studies, vol. 76, no. 1, pp. 29-51, 2019.

[5] P. R. Hobbs, K. Sayre, and R. Gupta, "The role of conservation agriculture in sustainable agriculture," Philosophical Transactions of the Royal Society B: Biological Sciences, vol. 363, no. 1491, pp. 543-555, 2007.

[6] P. Tarolli, M. Cavalli, and R. Masin, "High-resolution morphologic characterization of conservation agriculture," $C A$ TENA, vol. 172, pp. 846-856, 2019.

[7] E. Pareja-Sánchez, D. Plaza-Bonilla, M. C. Ramos, J. Lampurlanés, J. Álvaro-Fuentes, and C. Cantero-Martínez, "Long-term no-till as a means to maintain soil surface structure in an agroecosystem transformed into irrigation," Soil and Tillage Research, vol. 174, pp. 221-230, 2017.

[8] P. Omara, N. Macnack, L. Aula, and B. Raun, "Effect of longterm beef manure application on soil test phosphorus, organic carbon, and winter wheat yield," Journal of Plant Nutrition, vol. 40, no. 8, pp. 1143-1151, 2017.

[9] P. Omara, L. Aula, and W. R. Raun, "Nitrogen uptake efficiency and total soil nitrogen accumulation in long-term beef manure and inorganic fertilizer application," International Journal of Agronomy, vol. 2019, Article ID 9594369, 6 pages, 2019.

[10] A. D. Halvorson, B. J. Wienhold, and A. L. Black, "Tillage, nitrogen, and cropping system effects on soil carbon sequestration," Soil Science Society of America Journal, vol. 66, no. 3, pp. 906-912, 2002.

[11] R. Bhattacharyya, S. Kundu, S. C. Pandey, K. P. Singh, and H. S. Gupta, "Tillage and irrigation effects on crop yields and soil properties under the rice-wheat system in the Indian Himalayas," Agricultural Water Management, vol. 95, no. 9, pp. 993-1002, 2008.

[12] F. H. D’Emden, R. S. Llewellyn, and M. P. Burton, "Factors influencing adoption of conservation tillage in Australian cropping regions," The Australian Journal of Agricultural and Resource Economics, vol. 52, no. 2, pp. 169-182, 2008.

[13] P. Devita, E. Di Paolo, G. Fecondo, N. Di Fonzo, and M. Pisante, "No-tillage and conventional tillage effects on durum wheat yield, grain quality and soil moisture content in southern Italy," Soil and Tillage Research, vol. 92, no. 1-2, pp. 69-78, 2007.

[14] K. P. C. Rao, T. S. Steenhuis, A. L. Cogle, S. T. Srinivasan, D. F. Yule, and G. D. Smith, "Rainfall infiltration and runoff from an Alfisol in semi-arid tropical India. I. No-till systems. Approved as ICRISAT journal article no. 2053.1," Soil and Tillage Research, vol. 48, no. 1-2, pp. 51-59, 1998.

[15] B. Govaerts, M. Fuentes, M. Mezzalama et al., "Infiltration, soil moisture, root rot and nematode populations after 12 years of different tillage, residue and crop rotation managements," Soil and Tillage Research, vol. 94, no. 1, pp. 209-219, 2007.

[16] N. C. Hansen, B. L. Allen, R. L. Baumhardt, and D. J. Lyon, "Research achievements and adoption of no-till, dryland cropping in the semi-arid U.S. Great Plains," Field Crops Research, vol. 132, pp. 196-203, 2012.

[17] W. Gwenzi, J. Gotosa, S. Chakanetsa, and Z. Mutema, "Effects of tillage systems on soil organic carbon dynamics, structural stability and crop yields in irrigated wheat (Triticum aestivum L.)-cotton (Gossypium hirsutum L.) rotation in semi-arid Zimbabwe," Nutrient Cycling in Agroecosystems, vol. 83, no. 3, pp. 211-221, 2009.

[18] L. A. Ferreras, J. L. Costa, F. O. Garcia, and C. Pecorari, "Effect of no-tillage on some soil physical properties of a structural degraded Petrocalcic Paleudoll of the southern "Pampa" of Argentina," Soil and Tillage Research, vol. 54, no. 1-2, pp. 31-39, 2000.

[19] H. S. Rozas, H. E. Echeverría, G. A. Studdert, and F. H. Andrade, "No-till maize nitrogen uptake and yield," Agronomy Journal, vol. 91, no. 6, pp. 950-955, 1999.

[20] J. Arvidsson, A. Etana, and T. Rydberg, "Crop yield in Swedish experiments with shallow tillage and no-tillage 1983-2012," European Journal of Agronomy, vol. 52, pp. 307-315, 2014.

[21] L. M. Duzy, A. J. Price, K. S. Balkcom, and J. S. Aulakh, "Assessing the economic impact of inversion tillage, cover crops, and herbicide regimes in Palmer Amaranth (Amaranthus palmeri) infested cotton," International Journal of Agronomy, vol. 2016, Article ID 1524389, 9 pages, 2016.

[22] M. M. Mikha, M. F. Vigil, and J. G. Benjamin, "Long-term tillage impacts on soil aggregation and carbon dynamics under wheat-fallow in the central Great Plains," Soil Science Society of America Journal, vol. 77, no. 2, pp. 594-605, 2013.

[23] L. Aula, N. Macnack, P. Omara, J. Mullock, and W. Raun, "Effect of fertilizer nitrogen $(\mathrm{N})$ on soil organic carbon, total $\mathrm{N}$, and soil $\mathrm{pH}$ in long-term continuous winter wheat (Triticum Aestivum L.)," Communications in Soil Science and Plant Analysis, vol. 47, no. 7, pp. 863-874, 2016.

[24] J. S. Schepers, D. D. Francis, and M. T. Thompson, "Simultaneous determination of total $\mathrm{C}$, total $\mathrm{N}$, and ${ }^{15} \mathrm{~N}$ on soil and plant material," Communications in Soil Science and Plant Analysis, vol. 20, no. 9-10, pp. 949-959, 1989.

[25] SAS Institute Inc, Base SAS 9.4 Procedures Guide: Statistical Procedures, SAS Institute Inc, Cary, NC, USA, 2nd edition, 2013.

[26] M. C. S. Nogueira, "Orthogonal contrasts: definitions and concepts," Scientia Agricola, vol. 61, no. 1, pp. 118-124, 2004.

[27] H. Abdi and L. J. Williams, Contrast Analysis. Encyclopedia of Research Design, Sage, Thousand Oaks, CA, USA, 2010.

[28] G. B. Triplett and W. A. Dick, "No-tillage crop production: a revolution in agriculture," Agronomy Journal, vol. 100, no. S3, pp. S153-S165, 2008.

[29] J. W. Doran, "Soil microbial and biochemical changes associated with reduced Tillage1," Soil Science Society of America Journal, vol. 44, no. 4, pp. 765-771, 1980.

[30] B. Ghuman and H. S. Sur, "Tillage and residue management effects on soil properties and yields of rainfed maize and wheat in a subhumid subtropical climate," Soil and Tillage Research, vol. 58, no. 1-2, pp. 1-10, 2001.

[31] A. D. Halvorson, C. A. Reule, and R. F. Follett, "Nitrogen fertilization effects on soil carbon and nitrogen in a dryland cropping system," Soil Science Society of America Journal, vol. 63, no. 4, pp. 912-917, 1999.

[32] M. S. Dolan, C. E. Clapp, R. R. Allmaras, J. M. Baker, and J. A. E. Molina, "Soil organic carbon and nitrogen in a Minnesota soil as related to tillage, residue and nitrogen management," Soil and Tillage Research, vol. 89, no. 2, pp. 221-231, 2006.

[33] I. Ismail, R. L. Blevins, and W. W. Frye, "Long-term no-tillage effects on soil properties and continuous corn yields," Soil Science Society of America Journal, vol. 58, no. 1, pp. 193-198, 1994.

[34] W. R. Raun, G. V. Johnson, S. B. Phillips, and R. L. Westerman, "Effect of long-term $\mathrm{N}$ fertilization on soil organic $\mathrm{C}$ and total $\mathrm{N}$ in continuous wheat under conventional tillage in Oklahoma," Soil and Tillage Research, vol. 47, no. 3-4, pp. 323-330, 1998.

[35] J. Dhillon, M. R. Del Corso, B. Figueiredo, E. Nambi, and W. Raun, "Soil organic carbon, total nitrogen, and soil $\mathrm{pH}$, in 
a long-term continuous winter wheat (Triticum Aestivum L.) experiment," Communications in Soil Science and Plant Analysis, vol. 49, no. 7, pp. 803-813, 2018.

[36] I. Ortas, C. Akpinar, and R. Lal, "Long-term impacts of organic and inorganic fertilizers on carbon sequestration in aggregates of an Entisol in Mediterranean Turkey," Soil Science, vol. 178, no. 1, pp. 12-23, 2013.

[37] M. M. Mikha and C. W. Rice, "Tillage and manure effects on soil and aggregate-associated carbon and nitrogen," Soil Science Society of America Journal, vol. 68, no. 3, pp. 809-816, 2004.

[38] J. L. Havlin, D. E. Kissel, L. D. Maddux, M. M. Claassen, and J. H. Long, "Crop rotation and tillage effects on soil organic carbon and nitrogen," Soil Science Society of America Journal, vol. 54, no. 2, pp. 448-452, 1990.

[39] S. Malhi and H. Kutcher, "Small grains stubble burning and tillage effects on soil organic $\mathrm{C}$ and $\mathrm{N}$, and aggregation in northeastern Saskatchewan," Soil and Tillage Research, vol. 94, no. 2, pp. 353-361, 2007.

[40] C. A. Campbell, B. G. McConkey, R. P. Zentner, F. Selles, and D. Curtin, "Long-term effects of tillage and crop rotations on soil organic $\mathrm{C}$ and total $\mathrm{N}$ in a clay soil in southwestern Saskatchewan," Canadian Journal of Soil Science, vol. 76, no. 3, pp. 395-401, 1996.

[41] G. P. Lafond, F. Walley, W. E. May, and C. B. Holzapfel, "Long term impact of no-till on soil properties and crop productivity on the Canadian prairies," Soil and Tillage Research, vol. 117, pp. 110-123, 2011. 




International Journal of Food Science

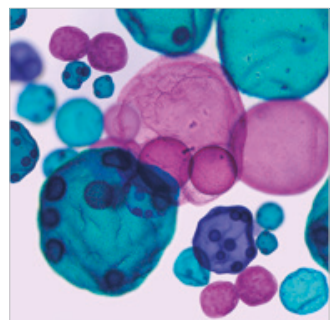

International Journal of Microbiology
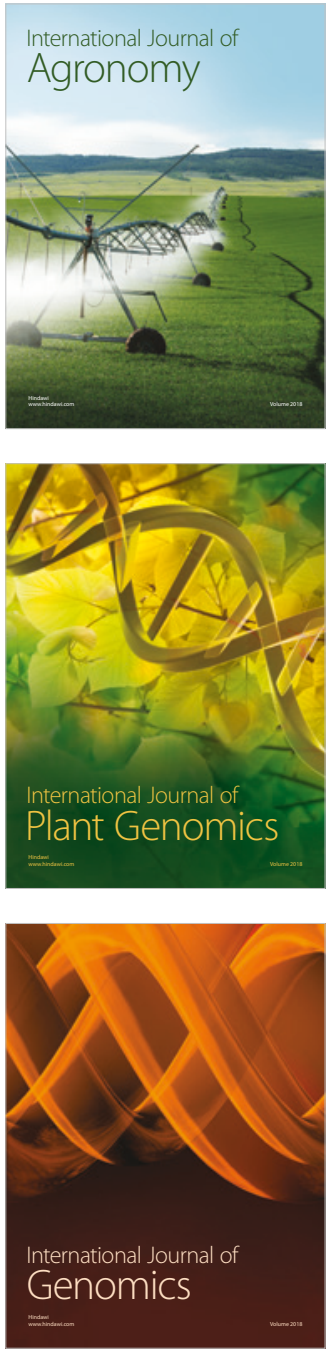

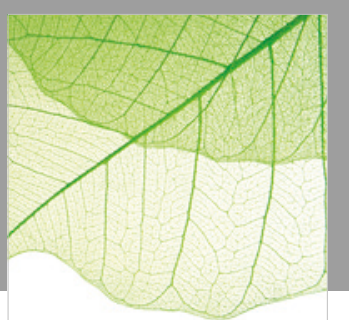

Journal of Botany
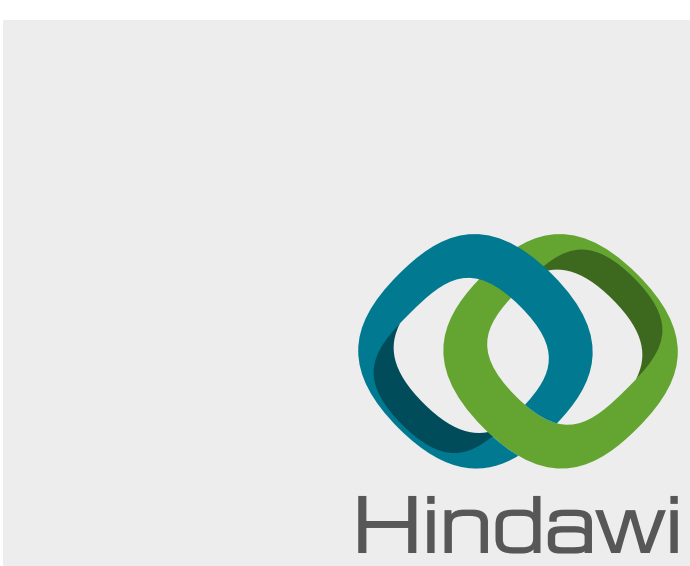

Submit your manuscripts at

www.hindawi.com
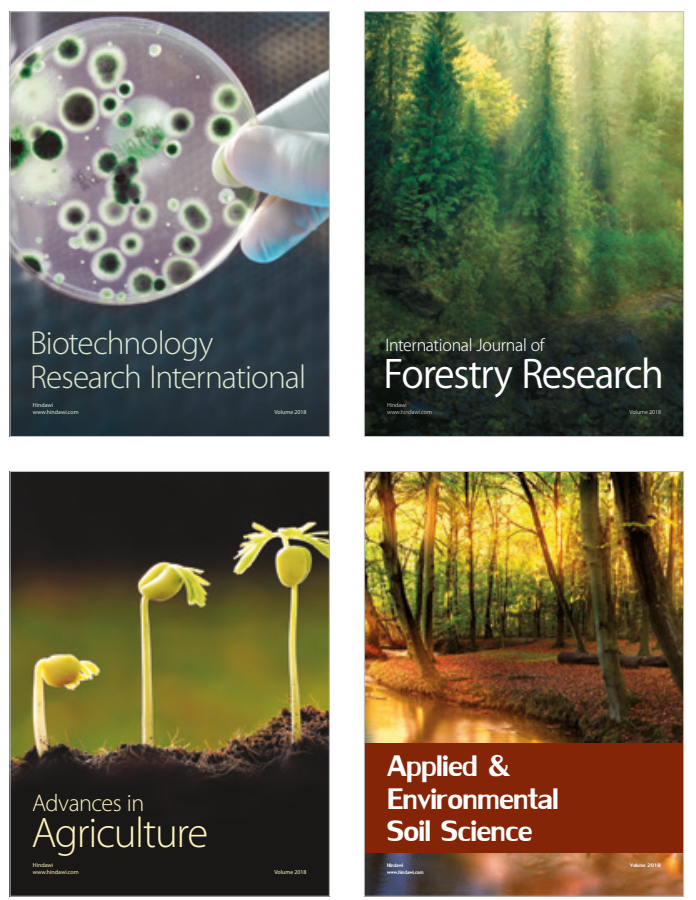



Scientifica



Veterinary Medicine International

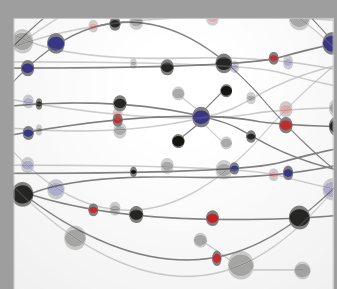

The Scientific World Journal
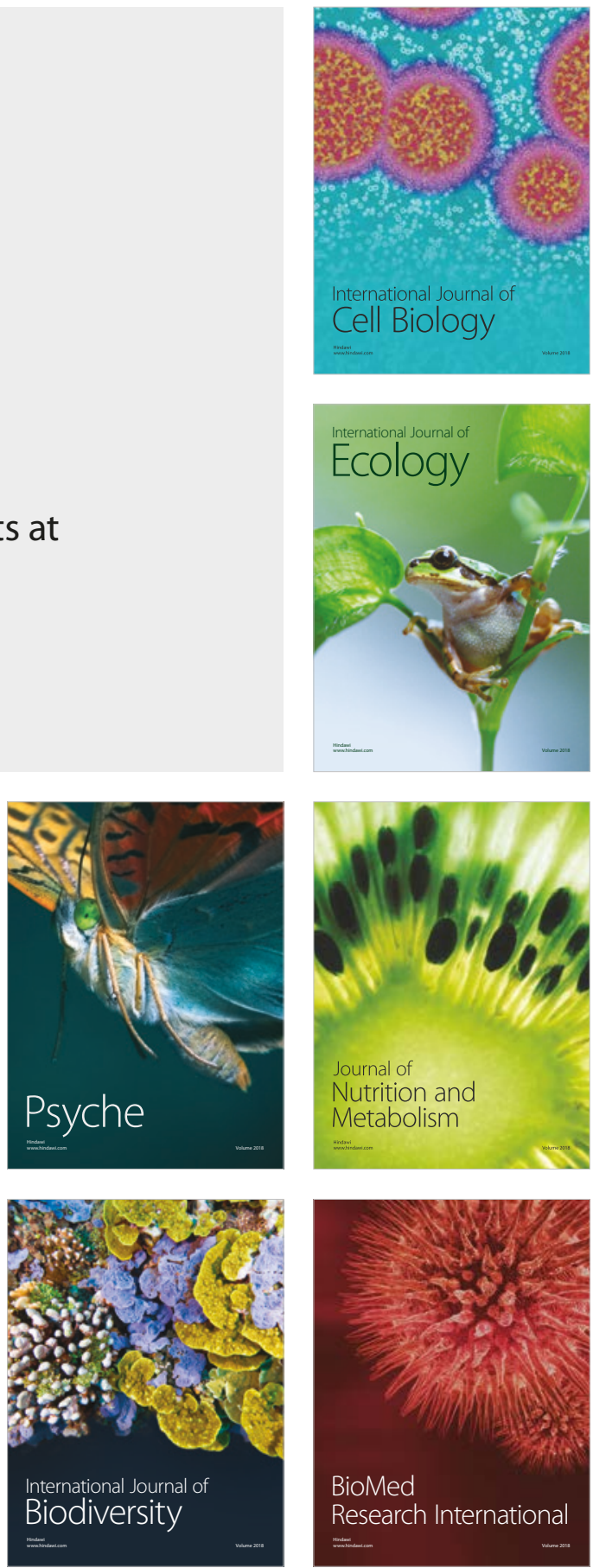